\title{
Using Maximal Isometric Force to Determine the Optimal Load for Measuring Dynamic Muscle Power
}

Email: Barry.Spiering-1@nasa.gov

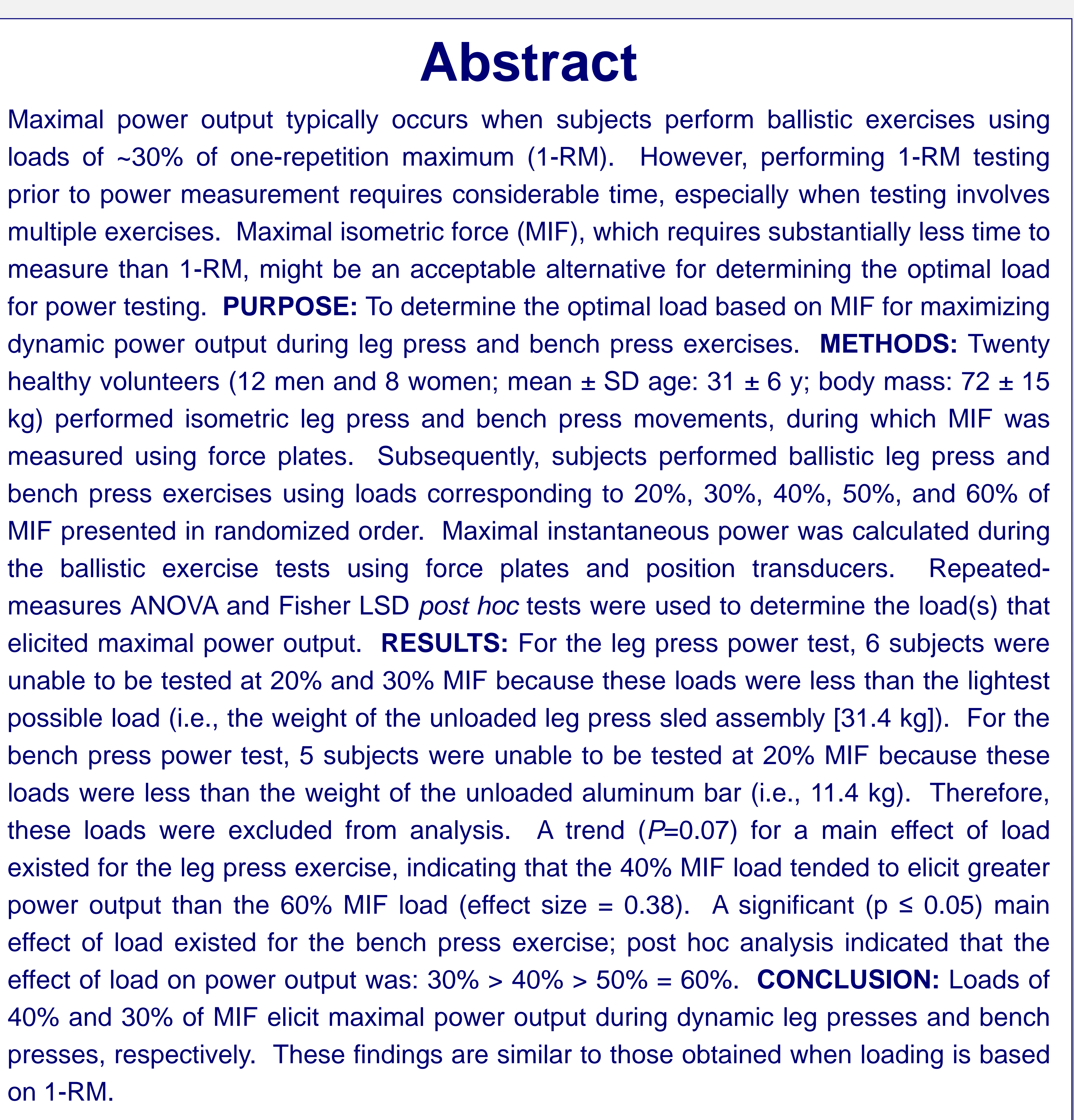

\section{Introduction}

Maximal power capabilities strongly predict functional (3) and athletic performance (4). Therefore, substantial research has sought to determine the optimal load with which to Therefore, substantial research has sought to determine the optimal load with which to lest maximal power capabilities. Although some controversy exists (2), peak
instantaneous power output is maximized when athletes perform ballistic movements using loads corresponding to $30 \%$ of 1-RM (1). However, measuring 1-RM is not always easible/appropriate. For instance, 1-RM testing prior to power measurement requires considerable time, especially when subjects are tested using multiple exercises; and 1-RM esting might be contraindicated in some populations (i.e., frail elderly, during injury ehabilitation, post-unloading)

Maximal isometric force (MIF) is an attractive alternative strength measure for determining the optimal load for power testing due to lower time requirements and the inherent safety purpose of this study was to determine the optimal load based on MIF for maximizing dynamic power output during ballistic leg presses and bench presses.

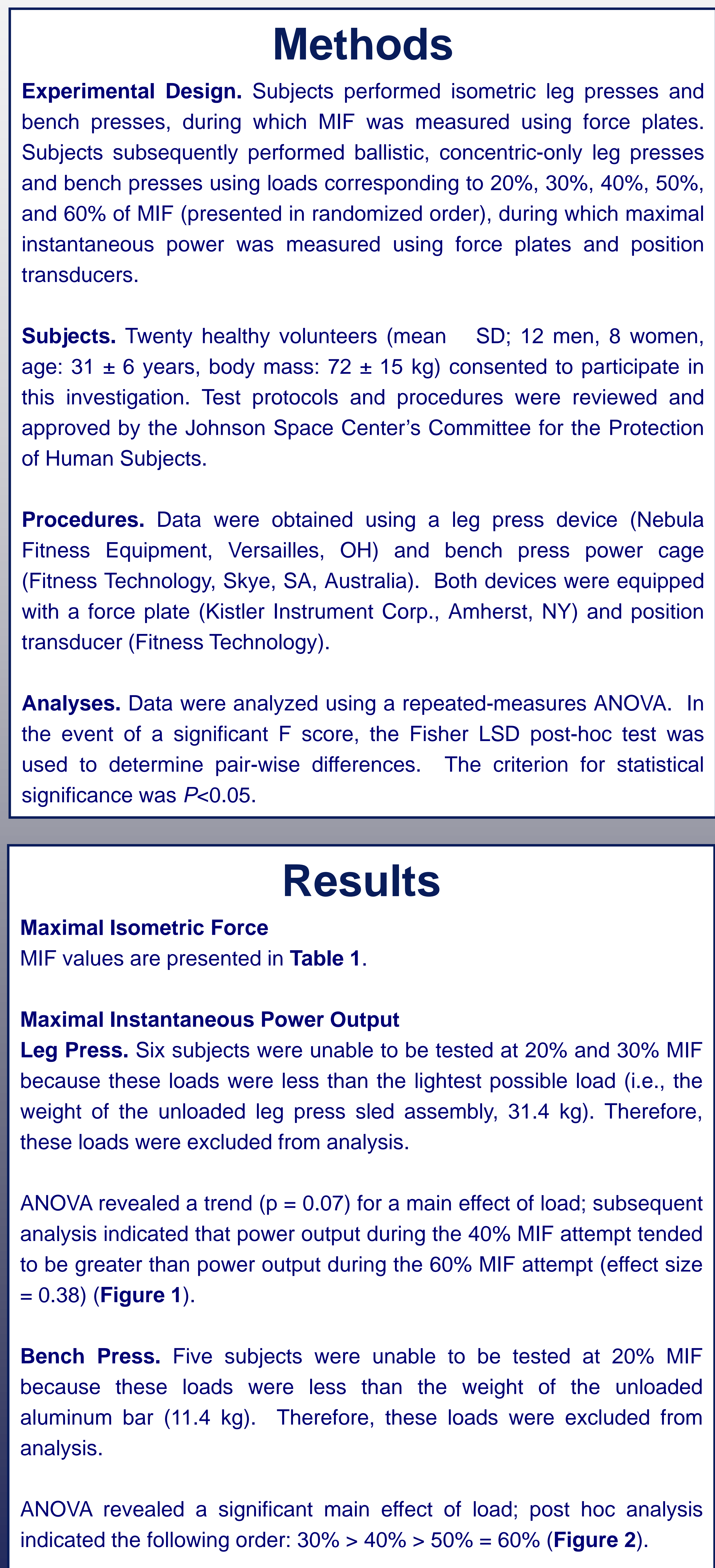

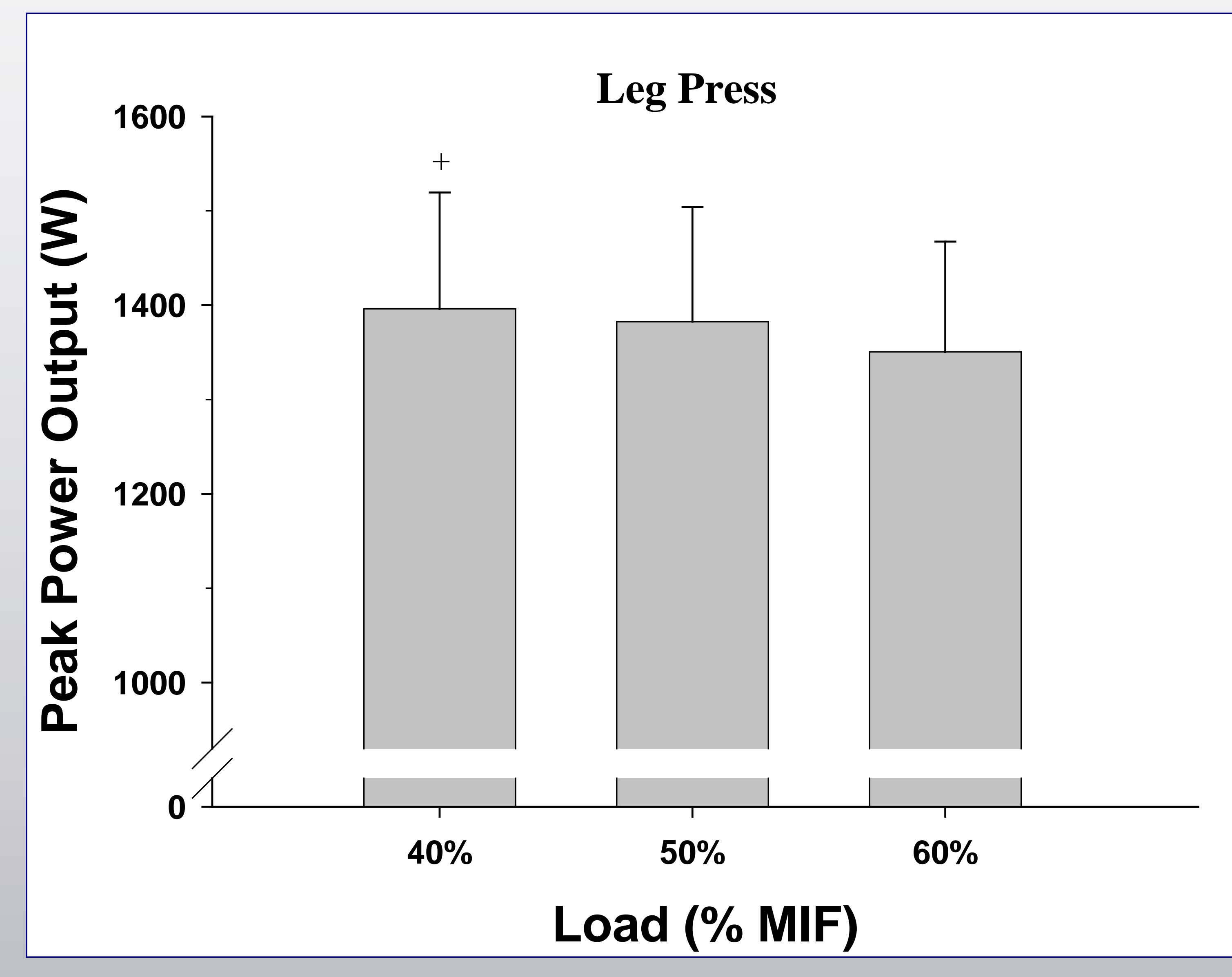

Figure 1. Peak power output (mean \pm SE) during ballistic leg presses using different loads based on a percentage of maximal isometric force (MIF). "+" denotes trend
compared to $60 \%$ MIF load.

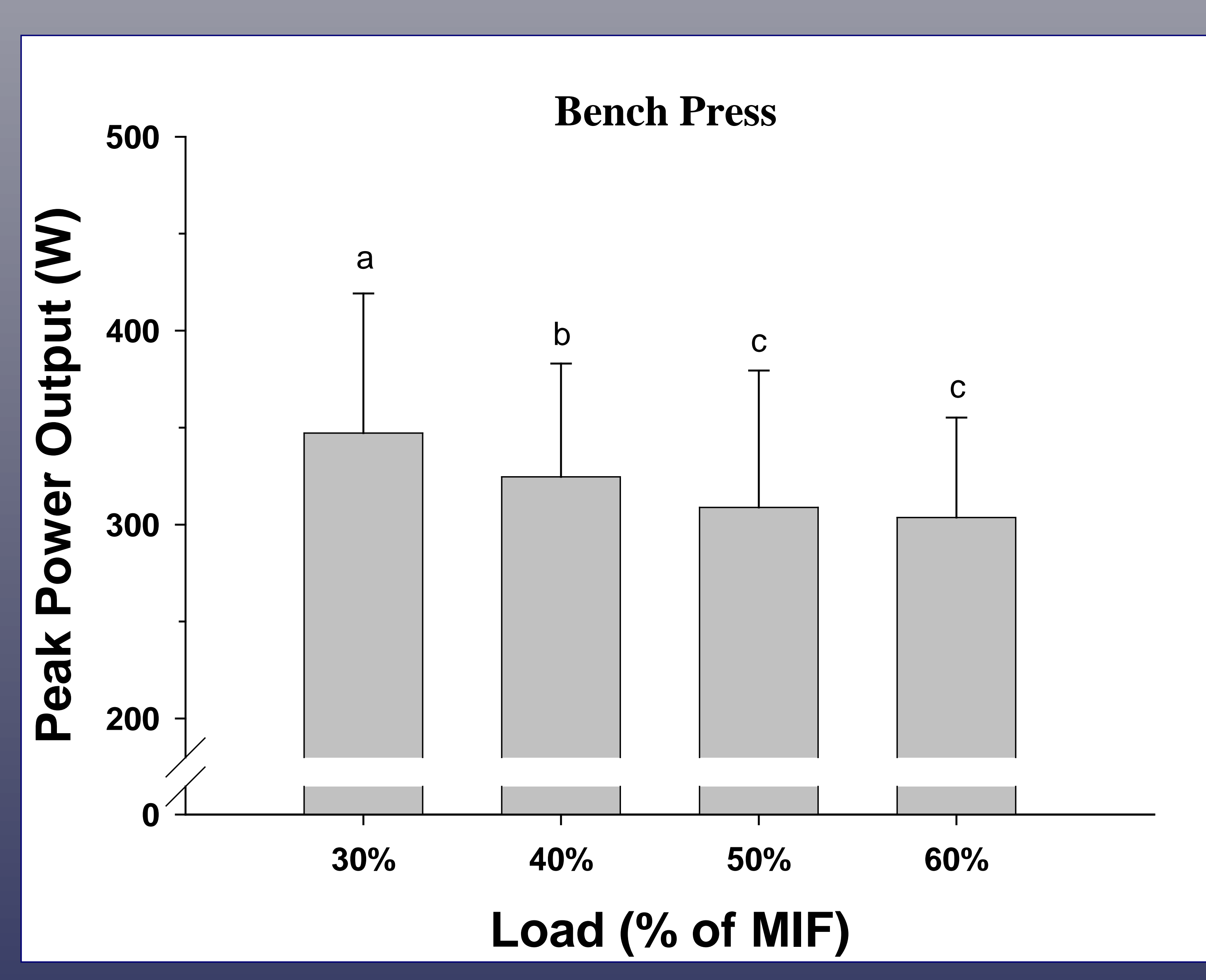

Figure 2. Peak power output (mean \pm SE) during ballistic bench presses using different loads based on a percentage of maximal isometric force (MIF). Unlike symbols
Table 1. Maximal isometric force values (mean $\pm \mathrm{SD}$ )

\begin{tabular}{|lcccc|}
\hline \hline & Leg Press $(\mathrm{N})$ & \multicolumn{3}{l|}{ Bench Press $(\mathrm{N})$} \\
\hline $\begin{array}{l}\text { Females } \\
(\mathrm{n}=8)\end{array}$ & 398 & 53 & 188 & 50 \\
\hline $\begin{array}{l}\text { Males } \\
(\mathrm{n}=12)\end{array}$ & 764 & 130 & 427 & 90 \\
\hline $\begin{array}{l}\text { Total } \\
(\mathrm{n}=20)\end{array}$ & 618 & 212 & 331 & 142 \\
\hline
\end{tabular}

\section{Conclusions}

Maximal isometric force (MIF), which requires little time and is inherentily safe to perform, can be used as an alternative strength measure for safe to perform, can be used as an atertinat
determining the optimal load for power testing.

Loads of $40 \%$ and $30 \%$ of MIF elicit maximal power output du ballistic, concentric-only leg presses and bench presses, respectively.

The optimal relative load for measuring peak power output (i.e., 30-40\% MIF) is similar to that which is recommended when loading is based on 1-RM (i.e., $>30 \%$ 1-RM)

\section{References}

Dugan EL, Doyle TL, Humphries B, Hasson CJ, Newton RU Determining the optimal load for jump squats: a review of meth Kawamori N, Haff GG. The optimal training load for the developm of muscular power. J Strength Cond Res. 2004 Aug;18(3):675-84. Puthoff ML, Janz KF, Nielson D. The relationship between lower extremity strength and power to everday walking behaviors in older 31.

Smirniotou A, Katsikas C, Paradisis G, Argeitaki P, Zacharogiannis E, Tziortzis $S$. Strength-power parameters as predictors of sprin performance. J Sports Med Phys Fitness. 2008:48(4):447-54.

\section{Acknowledgements}

This work was supported by the National Aeronautics and Space Administration

Would like to thank Kirk English, Mark Leach, and Leah Stroud for Invaluable assistance during data collection and an enthusiastic group of volunteers for participation in the study.
do not constitute endorsement by ACSM. 